\title{
Belas, recatadas e loucas: mulheres no Manicômio Judiciário de São Paulo
}

Brunno Henrique Moura e Mariana Soares Popperl

\section{Resumo}

A partir da análise dos doze prontuários das internas do Manicômio do Juquery, em São Paulo, o artigo tem por objetivo discutir o uso desta tipologia documental como fonte para o estudo da História de Gênero, levando em consideração a relação entre o desenvolvimento da Psiquiatria e o sexo feminino nas três primeiras décadas do século XX. Além disso, é importante ressaltar que esse conhecimento médico foi um instrumento importante para as políticas de controle social na Primeira República, que tinham por objetivo normatizar e disciplinar os indivíduos e seus comportamentos. Assim, as mulheres tornaram-se os principais alvos dos psiquiatras devido à especificidade atribuída à sua natureza diante da loucura, o que possibilitou o desenvolvimento de práticas intervencionistas que controlavam os corpos considerados desviantes e, no caso deste estudo, o corpo feminino.

Palavras chaves: Gênero - Loucura - Manicômio Judiciário - Mulheres Psiquiatria. 


\section{Introdução}

O grupo PET-História (Programa de Educação Tutorial) ${ }^{\mathrm{I}}$ da Universidade Federal de São Paulo desenvolveu, entre os anos de 20I4 e 20I5, o levantamento do acervo do Manicômio Judiciário do Estado de São Paulo (oficialmente chamado Hospital de Custódia e Tratamento Psiquiátrico Professor André Teixeira Lima) - localizado no município Franco da Rocha (Grande São Paulo) - com o objetivo de elaborar um instrumento de pesquisa referente a essa documentação a partir da confecção de uma planilha ${ }^{2}$. Para a realização desse projeto, foi estabelecida uma parceria com o Arquivo Público do Estado de São Paulo (APESP), que é responsável pela custódia do acervo. Para a elaboração dos estudos, o PET-História estabeleceu o recorte temporal da abertura do Hospital Psiquiátrico do Juquery, em I898, até o ano de I930, cobrindo a chamada Primeira República, devido a extensão documental 3 .

É importante ressaltar aqui que o presente trabalho é uma das possíveis abordagens a partir do acervo dos prontuários analisados. O grupo PET-História também desenvolveu outros trabalhos com diferentes eixos temáticos a partir desta tipologia documental, como, o uso das cartas anexadas aos prontuários, a análise dos diagnósticos dos internos, etc. Portanto, neste artigo a temática em questão concerne especificamente às internas do Manicômio Judiciário a fim de compreender a relação entre o desenvolvimento da Psiquiatria e o sexo feminino durante o século XX, salientando também que a ideia de inferioridade atribuída ao sexo feminino não ocorreu de forma imparcial, mas imbuída de elementos sociais, políticos e culturais da sociedade da época.

A documentação trabalhada está inserida em um contexto marcado por grandes mudanças nos âmbitos social e político. A abolição da escravidão, a proclamação da República, a imigração europeia e o processo de industrialização e urbanização marcaram o período de produção dessas fontes. Dentre as

I O PET é um programa do Ministério da Educação que envolve atividades de ensino, pesquisa e extensão. Vinculado ao Departamento de História da EFLGH/Universidade Federal de São Paulo, o grupo PET-HISTÓRIA UNIFESP foi criado em 2009. A realização dessas atividades esteve sob a tutoria dos seguintes professores: Prof. Dr. Denilson Botelho; Prof. Dr. Jaime Rodrigues; Prof. Dr. Marcia Eckert.

2 Sobre a pesquisa, cf. RODRIGUES, MIRANDA e; BOTELHO(20I6).

3 No subtítulo As mulheres dentro do Juquery: uma breve análise dos prontuários abordaremos com maior ênfase os prontuários, especialmente aqueles que se referem ao sexo feminino. 
diversas mudanças que ocorreram na consolidação da República, é importante destacar que, para este estudo, as políticas públicas voltadas ao controle social e a higienização, como, o controle de indivíduos desviantes e alienados a partir de espaços segregacionistas.

Além do problema da chamada desordem social, ainda era necessária a criação de espaços destinados ao tratamento dos doentes mentais, pois estes eram direcionados a instituições como a Santa Casa de Misericórdia e a Casa de Correção, o que prejudicava a administração do hospital e da cadeia devido à superlotação e à convivência entre os desatinados e os lúcidos (CUNHA, I986, p. 58). Diante da ausência de um espaço público destinado exclusivamente aos doentes mentais, surgem, na década de I850, duas importantes instituições psiquiátricas: o Hospício D. Pedro II, no Rio de Janeiro, e o Asilo Provisório de Alienados da Cidade de São Paulo.

Nesse contexto de surgimento das instituições psiquiátricas, o médico Francisco Franco da Rocha iniciava a sua carreira médica no Asilo de São Paulo e ganhava notoriedade na área da Psiquiatria brasileira. Em I898, com o apoio do Governo do Estado de São Paulo, conseguiu inaugurar o Hospital Psiquiátrico do Juquery no qual, em I9274 , deu-se a criação do Manicômio Judiciário, para onde eram destinados os indivíduos que haviam cometido algum crime e apresentavam perturbações mentais (CUNHA, I986, p. 85).

\section{A especificidade feminina diante da loucura}

Em decorrência dos eventos ocorridos nas últimas décadas do século XIX, Magali Engel afirma que:

[... a ampliação e a complexificação dos espaços urbanos, a Proclamação da República, entre outros aspectos, sinalizavam o advento de um novo tempo. Impunham, de acordo com as expectativas e interesses dominantes, a formulação e a execução de novas estratégias de disciplinarização e de repressão dos corpos e mentes sedimentados, por exemplo, sobre uma nova ética do trabalho e sobre novos padrões de moralidade para os comportamentos afetivos, sexuais e sociais (2000, p. 322).

4 A data em questão representa apenas a criação de um novo espaço físico no Juquery, pois no próprio acervo do Manicômio encontram-se prontuários anteriores a esse período. 
A partir dessas mudanças "consolidava-se o processo de medicalização da loucura, transformando-a em doença mental, em objeto exclusivo de um saber e de uma prática especializados, monopolizados pelo alienista" (ENGEL, 2000, p. 322). É possível observar que muitas experiências psiquiátricas atingiram certos indivíduos em detrimento de outros e algumas doenças despertaram um maior interesse médico, o que possibilitou o diálogo com outras especialidades da Medicina (ENGEL, 2000, p. 323). No caso do Brasil, por exemplo, devido às teorias organicistas para fundamentar a explicação dos distúrbios mentais, alguns procedimentos terapêuticos foram aplicados nos internos do Juquery, como a Malarioterapia e a Eletroconvulsoterapia. Segundo Gustavo Tarelow (2OII), esses procedimentos foram introduzidos na instituição com a entrada do médico Antonio Carlos Pacheco e Silva, dando continuidade ao trabalho desenvolvido durante duas décadas pelo médico Francisco da Rocha.

Tais práticas médicas corroboraram, posteriormente, a ideia que vinha se desenvolvendo acerca da inferioridade física e mental das mulheres a partir das investigações científicas sobre o corpo feminino e pelo argumento da determinação natural. Neste período, conforme a historiadora Ana Paula Vosne Martins $^{5}$, encontra-se um lugar exclusivo às mulheres: a maternidade.

Esse discurso ganha o reconhecimento na sociedade, que o corrobora, exigindo das mulheres o cumprimento do que naturalmente esperava-se delas: casar-se, tornarem-se mães e cuidarem de seu marido e filhos. Opor- se a estas funções significava ir contra a própria natureza, sendo a saúde física e mental das mulheres determinante para a execução dessas funções e o estado de "normalidade" que ela atestava. Essa "destinação" feminina é contraposta com a realidade da parcela de mulheres pobres da população que precisava trabalhar. Criam-se, desta forma, outros discursos opressivos a essas mulheres.

A partir desse contexto social, a construção psiquiátrica de uma íntima associação entre a fisiologia feminina e as perturbações mentais foi sustentada a partir dos estudos de anatomofisiologia. Os especialistas chegaram à conclusão de que as relações entre os órgãos sexuais e o cérebro estavam estabelecidas através da rede nervosa do corpo; portanto, qualquer estímulo sexual, mesmo que fraco e/ou contínuo, poderia refletir sobre o cérebro. Estas considerações foram compartilhadas entre muitas especialidades médicas, principalmente entre a Ginecologia e Psiquiatria (MARTINS, 20IO, p. 25).

5 Ver mais em Ana Paula Vosne Martins (2010). 
No contexto de descobertas acerca da natureza feminina e de sua sexualidade, observa-se uma linha tênue que separava a fisiologia da patologia, levando à conclusão de que, mesmo em estado de normalidade, o corpo feminino é doente. Estas considerações, a partir do início do século XX, fizeram os especialistas concluírem que alguns fenômenos fisiológicos exerciam uma ordem maior sobre a vontade das mulheres. Assim, o sexo era responsável pelas maiores transformações no corpo e no estado mental das mulheres e, portanto, a sexualidade se converteria no grande temor dos psiquiatras e ginecologistas (MARTINS, 2010, p. 27).

Com o objetivo de inibir o desejo sexual feminino, as mulheres foram submetidas a procedimentos terapêuticos, por exemplo, a extirpação do clitóris e a introdução de gelo, que tinham por objetivo erradicar as perturbações mentais. Mesmo que em alguns casos estas práticas não resultassem na eliminação ou cura das patologias, segundo Engel (2000, p.336), esta era a única forma viável para que a paciente retornasse a exercer o seu papel social. Além das práticas cirúrgicas, os fenômenos fisiológicos do corpo feminino - a menstruação, o parto e o pós-parto - foram considerados momentos propícios às manifestações das perturbações mentais.

Vale ressaltar que na primeira metade do século XX os ideais eugênicos ganhavam notoriedade com a fundação da Liga Paulista de Higiene Mental em I926. Um dos integrantes em destaque era o próprio médico Pacheco e Silva, o qual assumiu a direção do Juquery em I923. A partir das publicações dos Arquivos Paulistas de Higiene Mental, a Liga Paulista delimitou o seu objetivo: a educação eugênica da população como uma via de reduzir os doentes mentais entre a população paulista.

Afirmava-se que quem chegasse em solo paulista, logo constataria as particularidades da história do Estado, corporificadas em seus habitantes, em suas cidades e sobretudo em suas instituições médicas. Os estrangeiros que aportassem em 'terras bandeirantes' deveriam ter as melhores impressões da organização médico-sanitária realizada pelos serviços de higiene e suas instalações. Segundo os dirigentes, não poderia ser de outro modo, pois o estágio de desenvolvimento de um país se julgava pela expansão de sua instrução pública, que era preparo do futuro da nação, e pelo rigor de seus cuidados higiênicos, pois a saúde de seus habitantes garantiria o presente e preservaria o futuro. (TARELOW, 20II, p. 04-05)

A eugenia ganhava espaço no Brasil a partir de profissionais como Pacheco e Silva, que tinha prestígio na sociedade brasileira. Este médico, conforme 
Gustavo Tarelow (2OII), acreditava que a eugenia nada mais era que um complemento da própria teoria de Charles Darwin, tanto da seleção natural quanto da evolução das espécies. O objetivo, portanto, consistia em promover uma sociedade mais desenvolvida, isto é, com indivíduos sadios que estivessem isentos de qualquer resquício dos degenerados, entende-se aqui como degenerado as pessoas negras, homossexuais, deficientes físicos e mentais, etc.

Concomitante a esse contexto do desenvolvimento da Psiquiatria e a introdução dos ideais eugênicos no Brasil, consolidaram-se também novos padrões sociais no espaço urbano. Destaca-se, no início do século XX, a necessidade de estabelecer uma ordem social a qual se concretiza a partir da afirmação dos papéis do homem e da mulher permitindo o controle dos seus comportamentos.

No caso do sexo feminino, a mulher estava submetida a imposições diferenciadas do sexo masculino, ou seja, o seu papel estava relacionado ao âmbito doméstico, condicionado pela própria natureza feminina, o que a impossibilitava de realizar-se fora deste ambiente - diferentemente do papel atribuído ao homem que não poderia se realizar nesse meio. De acordo com as historiadoras Marina Maluf e Maria Lúcia Mott (I998), aqui se legitima o discurso de que o único lugar social destinado à mulher é o seu lar.

Logo, toda e qualquer mulher contrária às imposições sociais tornavase alvo da Psiquiatria. Negar o exercício de seu papel social ou não o exercer corretamente era considerada uma forma de ameaça à própria ordem social estabelecida. Contudo, vale ressaltar aqui que fatores como classe social e etnia, por exemplo, são fundamentais para compreender que nem toda mulher estava submetida às imposições da mesma forma. Outro ponto fundamental é reconhecer a mulher enquanto um agente ativo que também resiste às normas sociais, as mulheres não eram sujeitos passivos que ficavam inertes aos processos de normalização e normatização de seus corpos.

Observa-se, portanto, que a figura feminina exerce um papel fundamental na construção da ordem social no início do século XX. Além disso, o período em questão é marcado também pela presença da preocupação intervencionista de um saber médico que se interessa especificamente pelos corpos das mulheres. Ora como um objeto de investigação para a medicina a serviço da sociedade, ora como elemento principal para a constituição de uma família moralizada e higiênica, o conceito construído sob a mulher revela as facetas da sociedade do período em questão (CUNHA, I986, p. 34). 


\section{Os prontuários e seu uso como fonte}

Para o desenvolvimento dessa pesquisa utilizamos como principal fonte os prontuários do Manicômio Judiciário do Juquery que estão sob a guarda do Arquivo do Estado de São Paulo. É de extrema importância para o trabalho do historiador compreender as especificidades que utiliza, quais são seus limites e suas potencialidades. Dessa forma, são apreendidas todas as possibilidades que a fonte ofereceu para uma determinada pesquisa. Os prontuários são em sua origem um conjunto de documentos arrolados no decorrer de tratamento médico, produzido pelos agentes de saúde de uma instituição ${ }^{6}$.

O prontuário é uma documentação institucional, produzido para suprir as necessidades operacionais e burocráticas. Constitui-se por um conjunto de documentos de diversas tipologias, como exames, fichas de informações, cartas, etc. O uso de prontuários como fonte documental pela História teve seu início a partir da década de I960, advinda de uma revisão historiográfica da abordagem tradicional, que tinha como focos as instituições e o discurso produzido pelos médicos. Assim,

[...] [a] historiografia médica tradicional, que sob uma ótica predominantemente ufanista, tem se restringido, na maior parte das vezes, aos enfoques biográficos dos principais expoentes biográficos da atividade hipocrática e à "evolução" linear das instituições e do saber médico-epidemiológico. (BERTOLLI FILHO, I996, p. I73).

Partindo do viés analítico da História Social, analisar o enfermo como agente social contraria a abordagem tradicional que pensava nas instituições e nos médicos como único objeto de trabalho. Para essa mudança ocorrer foi necessário modificar as perguntas que eram feitas à fonte, apresentando outras dificuldades no uso do prontuário, como, a falta de dados e de continuidade dessas informações.

O prontuário, assim como qualquer fonte no trabalho do historiador, não é neutro. É importante contextualizar sua produção e seu objetivo; assim, torna-se possível a análise do discurso veiculado no documento.

6 Sendo assim, temos como uma definição dos prontuários dos agentes produtores como: "Conjunto de documentos padronizados e ordenados, onde devem ser registrados todos os cuidados profissionais prestados aos pacientes e que atesta o atendimento médico a uma pessoa numa instituição de assistência médica ou num consultório médico. É também o documento repositório do segredo médico do paciente." CRM-SG (20I6). 
Elaborado por um especialista médico com o objetivo de registrar uma doença mental, cabia a legitimação (ou não) da doença na documentação do posicionamento do especialista, influenciado por suas convicções médicas e sociais :

[...] muitas das apreciações que poderiam ser consideradas propriamente tributárias do hermético conhecimento médico - biológico tendem a derivar para observações comprometidas com a sensibilidade social dominante no período que a documentação foi produzida (BERTOLLI FILHO, I996, p.I73).

Dessa forma, ao se trabalhar com o prontuário como fonte, deve-se considerar questões como qual instituição o produziu, quais eram os objetivos dessa instituição, quais tipologias integram esse corpus documental, como se estrutura, quais informações se repetem, construindo uma análise ampla da documentação como um todo e suas especificidades.

\section{As mulheres dentro do Juquery: uma breve análise dos prontuários}

Este artigo é um dos produtos finais da parceria entre o grupo PET - História e o Arquivo do Estado de São Paulo que tinha por objeto os prontuários do Manicômio Judiciário do Juquery. Durante o projeto desenvolvemos um banco de dados para auxiliar o pesquisador tendo por base uma bibliografia pertinente e a análise das fontes a partir de amostragens. Este banco de dados foi consolidado em uma planilha de Excel com informações chaves presente nos prontuários ${ }^{7}$.

Dos 35I prontuários de ambos os sexos no período recortado, apenas I2 referem-se ao sexo feminino. Gustavo Tarelow (20II, pp. I4-5) ao analisar os dados referentes às internações no Juquery obteve os mesmos resultados díspares de internações ao comparar indivíduos do sexo masculino e feminino. $\mathrm{O}$ autor atribui esse fenômeno a um amplo aspecto de questões so-

7 As informações que constam no banco de dados do grupo PET - História são: número da caixa; número do prontuário; nome do paciente/interno; iniciais do nome do mesmo; vulgo; iniciais do vulgo; sexo; dados étnicos/cor; nacionalidade; naturalidade; estado civil; profissão; religião; instrução; pai (iniciais do nome do pai); mãe (iniciais do nome da mãe) ; local e procedência; motivo da saída; identificação; anamnese e exames; exames psíquicos e evolução; diagnóstico; observações; resumo; data de inserção do registro. 
ciais do período, como, os papéis sociais destinados a homens e mulheres. De modo a compreender que os homens circulavam mais no âmbito social e, por conseguinte, estavam mais expostos a situações de conflitos do cotidiano, que poderiam resultar na sua internação aos espaços disciplinares, como prisões e manicômios ${ }^{8}$.

Dentre os 12 prontuários, predominam as internas brasileiras (oito), seguidas por duas italianas, uma japonesa e uma portuguesa; cinco eram brancas, quatro pardas, uma negra, uma amarela e para uma não consta tal informação. Ao realizar uma leitura seriada dos prontuários, é possível perceber que a questão étnico-racial, especificamente a cor que consta nos prontuários, é uma atribuição sem padronização, dessa forma, a atribuição varia de acordo com o responsável pela inserção de informações.

As idades das internas estão ligadas ao seu estado civil, sendo que em sua maioria eram jovens e casadas. Oito mulheres tinham idade entre 20 e 30 anos, duas entre 3I e 40 anos, uma entre 4I a 50 anos e uma não teve registrado esse dado. Seis eram casadas, três viúvas, duas solteiras e uma sem informação.

A ocupação em serviços domésticos era predominante: nove mulheres exerciam essa função e para outras três não constam dados. Segundo Tarelow (2OII, p.II7), as mulheres que tinham por profissão "serviços domésticos" voltavam-se aos cuidados do lar, ou "donas de casa" no entendimento contemporâneo.

Os dados relativos à religião indicam que quatro mulheres foram declaradas católicas e para as restantes não consta. Apesar da importância da religião na sociedade, essa informação muitas vezes era negligenciada nos prontuários: em comparação com o número total de internos, homens e mulheres, $44 \%$ foram declarados católicos, enquanto $49 \%$ correspondem a registros de outras religiões ou sem declaração.

Segundo Tarelow os diagnósticos permitem diferentes linhas de análise, configurando-se como um assunto complexo, pois em alguns casos uma mesma doença possui mais de uma nomenclatura, assim como são entendidas de acordo com as mutantes concepções científicas.

8 Em contraponto a construção de uma feminilidade ideal (em que o corpo feminino está voltado para o ambiente doméstico, ao cuidado, a maternidade), há uma construção de uma masculinidade pautada na virilidade e na violência, permitidas tanto no ambiente público como privado. O que consequentemente gera ao homem uma realidade social diferenciada da mulher, estando mais exposto, por exemplo, a crimes como o homicídio. Ver mais em OLIVEIRA, 2004. p.IOI. 
É importante frisar que o modelo de classificação das doenças mentais utilizadas no Juquery também mantinha uma ligação evidente com as concepções médicas e científicas dos diretores daquele hospício. Dada a diretriz pelo diretor do hospício, os demais psiquiatras tinham a responsabilidade de seguir o modelo oficial da instituição, com raras exceções (20IIb, p. 58).

São cinco os diagnósticos presentes no recorte aqui definido: a cinco mulheres foi atribuída demência precoce, uma sofria de debilidade mental, uma era imbecil, uma tinha loucura moral, uma foi diagnosticada com síndrome paranóide, parapheria (sic, parafrenia), outra com psicose maníaca e uma não foi classificada. Dentre os temas possíveis de explanação dos prontuários como fonte os diagnósticos, inserem-se tais diagnósticos como uma das possibilidades de maiores desdobramentos em uma pesquisa. Um dos aspectos passíveis de pesquisa é a incidência de determinados diagnósticos entre homens e mulheres até I930. Por exemplo, casos de alcoolismo (que correspondem a $5,2 \%$ dos diagnósticos) e da sífilis (com $4 \%$ de diagnósticos). Essa diferença já foi destacada por Gustavo Tarelow (20IIb, p. 60-I) ao analisar as terapias aplicadas às doenças com maiores incidências no Hospício do Juquery. Isto é, determinadas patologias que se referem a certos comportamentos na sociedade estão intrinsecamente ligados ao sexo do paciente ${ }^{9}$.

Um ponto que faz diferir os internos é o crime cometido. Sobre os internos do Manicômio Judiciário incide o estigma do crime, sendo o assassinato recorrente. Os crimes levantados no caso das internas podem ser assim descritos: quatro mataram o marido, outras quatro cometeram infanticídio, uma matou seu pai e em três casos não consta o motivo da internação.

Os crimes cometidos por mulheres estão relacionados à esfera privada, voltados a familiares próximos, como maridos e filhos. Diante dessa questão, deve-se levar em conta o espaço social em que a mulher estava inserida. $\mathrm{O}$ ambiente doméstico era o espaço destinado a ela, e quanto mais jovem, a casa servia para proteção de sua moral, sendo que depois de casada ela devia se concentrar nos cuidados com o marido e os filhos. "À mulher, restavam as tarefas estratégicas da reprodução e da conservação da família e do lar [...] conforme exigiriam sua própria determinação biológica e as inclinações naturais" (CUNHA, I989, p. I25).

9 O diagnóstico de loucura moral é um tema extremamente intrigante, infelizmente não será possível abordar tendo em vista o limite de páginas deste artigo. Contudo, Cunha (I986, p. II3) e Tarelow (20II, p. 60) tratam deste assunto mais demoradamente. 
Entretanto, quando se discute as mulheres, em seu sentido mais generalizador, é importante destacar que este não é um grupo homogêneo, havendo clivagens socioeconômicas e raciais que modificavam sua realidade e os padrões impostos sobre seus corpos. A cobrança de determinados comportamentos está intimamente ligada ao meio social da mulher em questão, assim como o tratamento médico relegado a elas.

No caso das mulheres negras, sua inferioridade entre os inferiores revela-se como algo inscrito em sua própria condição biológica, na natureza feminina que ela, em alguma medida, compartilha com as mulheres brancas (já que aquelas não enlouqueciam mais que os homens apenas por se manterem 'protegidas' no interior do lar e da família) (CUNHA, I989, p. I25).

A interna O.S., 22 anos, preta, casada e exercendo a profissão de serviços domésticos, foi internada no Juquery em agosto de $1925^{\text {Io }}$. Foi transferida da Penitenciária sob a acusação de assassinar seu marido a machadadas. Recebeu o diagnóstico de demência precoce. Em seu prontuário consta cópia dos depoimentos das testemunhas, sendo que todas afirmaram o ato cometido pela ré. Segundo seu próprio relato, ela cometeu tal crime diante das indagações do marido sobre a maneira pela qual O.S. educava os filhos do casal. Apesar das partes apresentadas serem confusas, é possível perceber o julgamento moral contido na transcrição da fala da interna, "Eu estava processada, mulher da lei; fiquei a rapariga mais regateira do mundo; depois veiu (sic) os filhos $[\ldots]^{\prime \prime}$.

A interna se intitulava "a rapariga mais regateira do mundo", auto caracterização pouco usual para mulheres em um período de intensa repressão sexual, sobretudo quando se referiam a si mesmas. Sob seu discurso recaíram não apenas o julgamento médico, mas também as imposições morais do que era esperado do sexo feminino.

Ao realizar essa breve análise de dados dos prontuários de indivíduos do sexo feminino no Manicômio Judiciário do Juquery é possível perceber pontos em comuns dessas mulheres, contudo, sem perder a individualidade da trajetória de cada interna. Há, nessa análise, o Manicômio Judiciário como

Io Por decisão dos autores os nomes das internas não serão divulgados por se tratar de uma documentação contemporânea e também pela especificidade da fonte. Compreendemos que os prontuários médicos são considerados sigilosos e possuem informações de cunho fortemente pessoal.

II APESP/MJ, caixa 20, prontuário DAP 3I9, f. 8. 
uma instituição normatizadora, contudo, devemos citar que existem indivíduos que, para além do título atribuído de internas, são mulheres que possuem histórias, que existiram e resistiram.

\section{v. Considerações finais}

A documentação, analisada brevemente neste artigo, possui uma vasta possibilidade do desenvolvimento de pesquisa, apesar da diminuta quantidade de prontuários. Tendo como objetivo central a discussão do uso dos prontuários como fonte da história, elaboramos um panorama geral que demonstra as mais variadas vertentes de pesquisas.

Observamos que muitos assuntos devem ser averiguados com mais profundidade, por exemplo, compreender de modo mais elaborado a disparidade de prontuários entre homens e mulheres e também realizar um trabalho de fôlego ao se debruçar sobre os diagnósticos tendo em vista o gênero como análise central.

A partir dessas considerações, os prontuários aqui apresentados se mostram uma fonte documental fundamental para compreender questões pertinentes ao campo de estudos sobre a loucura, sendo possível abordar esta documentação de variadas formas como institucional, socioeconômica, estabelecer recortes de gênero, etc.

\section{Referências}

APESP/MJ, caixa 20, prontuário DAP 319.

APESP/MJ, caixa 22, prontuário DAP 294.

BERTOLLI FILHO, C. Prontuários médicos: fonte para o estudo da história social da medicina e da enfermidade. História, Ciências, Saúde-Manguinhos, Rio de Janeiro, v. 3, n.I, I996.

GRM-SG: Conselho Regional de Medicina do Estado de Santa Catarina. Manual de orientação ética e disciplinar. 2000. Disponível em: <http://www.portalmedico. org.br/Regional/crmsc/manual/parte3b.htm>. Acesso em: 06 fev. 2016.

CUNHA, M. C. P. Espelho do mundo: Juquery, a história de um asilo. Rio de Janeiro: Paz e Terra, I986.

. Loucura, Gênero Feminino: as mulheres do Juquery na São Paulo do início do século XX. In: Revista Brasileira de História. São Paulo, v. 9, n I8,I989, p.I2I-I 44 
ENGEL, M. G. Psiquiatria e Feminilidade. In: Mary Del Priore. (Org.). História das mulheres no Brasil.8. ed. São Paulo: Contexto, 2000.

MALUF, M.; MOTT, M. L. Recônditos do Mundo Feminino. In: SEVCENKO, N. (Org.) História da Vida Privada no Brasil - República: da Belle Époque à Era do Rádio. São Paulo: Companhia das Letras, I998. v. 3.

MARTINS, A. P. V. Um sistema instável: As teorias ginecológicas sobre o corpo feminino e a clínica psiquiátrica entre os séculos XIX e XX. In: WADI, Y. M. (Org.); SANTOS, N. M. W. (Org.). História e Loucura: saberes, práticas e narrativas. I. ed. EDUFU, 2010.

OLIVEIRA, P. P. A construção social da masculinidade. Belo Horizonte: Editora UFMG/ Rio de Janeiro: Instituto Universitário de Pesquisas do Rio de Janeiro; 2004. BOTELHO, D.; MIRANDA, M. E.; RODRIGUES, J. O acervo de prontuários do Manicômio Judiciário do Estado de São Paulo (I903- I930). Revista Fontes. n. 4. 2016, p. I4-70.

TARELOW, G. Q. A moral, a política e algumas questões científicas presentes no Hospital do Juquery: Abordagens de Pacheco e Silva (I923-I950). Histórica - Revista Eletrônica do Arquivo Público do Estado de São Paulo. São Paulo, v. 5I, $20 \mathrm{IIa}, \mathrm{p} . \mathrm{I}-\mathrm{I} 2$.

. Entre febres, comas e convulsões: As terapias biológicas no hospital do Juquery administrado por Pacheco e Silva (I923 - I937). 20Irb. Dissertação (Mestrado) - Curso de História Social, História, Universidade de São Paulo, São Paulo, 2OII.

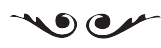

Brunno Henrique Moura é graduando em História pela Universidade Federal de São Paulo. hbrunnomoura@gmail.com.

Mariana Soares Popperl é graduanda em História pela Universidade Federal de São Paulo. marianapopperl@yahoo.com.br 